\title{
Repensarla formacion humana en la modernidad
}

\author{
Saúl Ernesto García Serrano ${ }^{1}$
}

\section{Resumen}

La educación en la vida universitaria, debe ser un espacio y un tiempo para adquirir sabiduría y así humanizar el trabajo, la ciencia, la profesión, la cultura. Este es el paradigma de la universitas, dejado desde la edad media.

Si no se realiza esta labor, la educación y los entes formadores pueden caer en la trampa de formar "monstruos educadísimos", pero sin sapienza, sin virtud, sin capacidad de contemplar y tener un claro sentido de la vida.

En la modernidad la educación superior debe propender por mantener el equilibrio de la transmisión, la formación de las competencias laborales que provienen de la disciplina epistemológica de cada ciencia y de las competencias para la vida, aquellas que se enlazan con el estudio de las humanitates.

El estudio de las "humanidades" en el contexto de la modernidad se mueve bajo el influjo de un pensamiento blando, la difusión de ideologías y la tendencia a la convergencia y por eso hay que repensar sus desafíos: ¿Cómo puede entonces contribuir la formación humanista a crear un pensamiento convergente para que la humanidad se una desde lo diverso manteniendo su identidad?, ¿Se puede rescatar lo excluido por el pensamiento débil-blando, para pasar del reino de la doxa al reino de las ideas inmutables?, ¿Es posible hablar al mundo de la juventud universitaria de una cultura de unidad humanística?, ¿Cuál debe ser el rol del intelectual académico hoy en la contribución de educar personas, ciudadanos y profesionales?

Palabras clave: educación, humanidades, universidad, modernidad. 


\title{
Rethinking education in the modern human formation
}

\begin{abstract}
Education in university life should have the space and time to acquire wisdom and humanize work, the sciences, professions, and culture. This is the paradigm of the universities, from the media age.

If this task is not accomplished, the educators and the instructors can fall into the trap of being "education monsters" but without virtue, without the ability to contemplate and have a clear sense of life.

Modern higher education must advocate for a balanced education; the cultivation of work skills that come from each discipline of science, and life skills, those that are related to the study of humanities.

The study of the humanities in the context of modernity reaches beyond the influence of common thought, the spread of ideologies and the tendencies for convergence, so we need to rethink their challenges: How can humanities education contribute to creating convergent thinking that mankind is one while maintaining its identity of diversity? Is it possible to rescue the excluded ideas in order to pass from the kingdom of doctrine to the kingdom of immutable ideas? Is it possible to talk to the world of university youth of a united human culture? What should be the role of intellectual academics today regarding the contribution of educated people, citizens, and professionals?
\end{abstract}

Keywords: pedagogy, reeducation, distance education.

Recibido: 04/09/2014

Aceptado: 17/11/2014

\section{Desde lo superior: Educacion de 'maximos'}

"Las notas esenciales del hombre del medioevo, hecho para lo superior y en lo superior, son la prudencia y la honestidad"

(Alfonso Borrero)

La universidad contribuye a construir una nueva ciudadanía desde 'máximos' de justicia, tesis que propongo lejos de entrar en controversia con el gran aporte de la ética de mínimos. 
Formar para una ciudadanía activa desde la universidad implica que el alma mater forme en su 'vientre', ciudadanos capaces de implantar una "sociedad justa" (Salazar, 2000:3), basada en la primacía de unos máximos de justicia pues la universitas tiene en su tradición educativa el formar a sus estudiantes para vivir máximos, esto es: ciudadanos que salen con un alto concepto de la dignidad humana comprendida y contemplada por la razón, ciudadanos que son capaces de vivir y defender los valores de la autenticidad, la libertad, la compasión, la responsabilidad, la tendencia a la igualdad de condiciones, el respeto por la diferencia, y en definitiva ciudadanos apasionados por cuidar, defender y promover la vida.

Considero que si la educación se limita a enseñar los mínimos, el individuo en su proceso educativo llega a vivir por debajo de ellos, y así lo mínimo no se convierte en garantía de justicia: ¿Cual es lo mínimo en las sociedades pluralistas y relativistas del concepto de la dignidad humana?, ¿De la autenticidad, la solidaridad, o la defensa de la vida?

Querer implantar una sociedad justa sobre mínimos es entrar en el peligro del relativismo de los valores y de la justicia; por eso considero que hay que hablar desde la formación humanística en la universidad de una educación que favorezca la primacía de unos máximos de justicia, pues ellos pueden garantizar una sociedad justa.

El problema de la educación superior sea de instituciones de inspiración laical, estatal o religiosa, en la formación de ciudadanos activos desde una educación de 'máximos', es cuando contemplamos que la sociedad justa no aparece en el panorama de nuestra civilización y de nuestro país, pues la sociedad injusta sigue prevaleciendo sobre la sociedad justa, y los máximos de justicia parecen ser ignorados por los profesionales egresados de las universidades.

¿Qué está pasando en el tiempo de formación que dura un estudiante en pregrado o posgrado?, pues hoy debemos cuestionar o problematizar sus resultados, con el ideal de lo que debe ser la educación, "pues ella es la puerta de entrada para todas las demás conquistas sociales. Sin educación la gente no encuentra trabajo, no sabe cómo cuidar su salud, no descubre mecanismos para salir de la miseria, no sabe aprovechar el tiempo libre, no se beneficia de las cosas buenas que su cultura le ofrece" (Salazar, 2000:3).

Puedo entonces afirmar que la universidad y la formación humana están llamadas a cuestionarse: ¿Qué está haciendo hoy con la educación de máximos para favorecer una sociedad justa por medio del conocimiento asimilado de sus egresados? 


\title{
2. Formar para el trabajo y para la vida
}

\author{
“¿Deben prepararse competidores aptos en el mercado laboral \\ o formar hombres completos?"
}

(Fernando Savater)

El momento de formación académica en la universidad, debe convertirse de forma imperiosa en un tiempo en donde se adquiere no solo competencias profesionales sino también competencias actitudinales, es decir aquellas competencias en donde se adquiriere y se vive la sophia: "Competencias relacionadas con el desarrollo del pensamiento crítico, el discernimiento moral, para convivir y comprender al otro, para emitir un juicio ético y estético" (Ministerio de educación nacional e Icfes, 2001: 89-92).

El desarrollo educativo y cultural de los griegos nos deja el legado de que "la enseñanza griega clásica se interesó en el hombre como tal, no en la preparación de técnicos en oficios especializados" (Borrero, 1994). La universidad y las ciencias humanas tienen por lo tanto un cometido tan importante en la formación integral del estudiante, del profesional: ayudarlo a su desarrollo ético para el bien de la nación (Ministerio de educación nacional, 1992:6).

La formación para el trabajo y para la vida, implica precisar el sentido metafísico del valor del trabajo y del acto de trabajar: trabajar es un acto social de servicio (trabajar es trabajar con otros y para otros); trabajar es un acto que tiene una dimensión objetiva (es el medio de subsistencia, técnica trasformación del entorno y apropiación de bienes) (Juan Pablo II, 1981:5.7); trabajar es un acto personal-subjetivo (es una actividad, una experiencia y derecho fundamental (Declaración Derechos Humanos, 1948:23), base para el concreto ejercicio de muchos otros derechos propios del ciudadano. El que trabaja, forja su propia humanidad, se trasforma a sí mismo, se hace mejor; en el trabajo se realiza una “autocreación" (Buttiglione,1984:8), se perfecciona.

La formación para el trabajo y para la vida, está unida además, a una tarea a desarrollar desde la universidad sobre tres tentaciones que tendrá siempre que afrontar el futuro profesional: la primera tentación es el peligro de convertir el saber de su ciencia en un ídolo, pues "el estudio hace al hombre poderoso" (Borrero, 1994: 30), (aquí la persona termina viviendo para el trabajo, se esclaviza de este valor, se engríe y se engorda de sus títulos y ciencia); la segunda tentación es la de convertir en ídolo, el poder que viene del tener bienes, dinero, propiedad privada, pues el saber da poder (aquí la persona termina viviendo para atesorar tesoros en la tierra, la sed de avaricia y enriquecimiento crece sin control, se trabaja entonces únicamente para hacer dinero como sea); y la tercera tentación es la de convertir la empresa en el centro de la vida (aquí la persona vive para la empresa que en algunos casos se vuelve su hogar. La persona cree que sin la empresa no puede vivir, no hay más salidas, etc). 
Estas tres tentaciones se hacen más dramáticas, frustrantes y causantes de grandes problemas sicológicos, civiles, penales, sociales, de sentido de la vida, para la persona del profesional, cuando la existencia le da la lección de que en esos tres ídolos en donde ha centrado todo el sentido de la vida todas sus fuerzas, caen, desaparecen o le pagan mal.

La formación académica-profesional, entonces, debe gestar y hacer real una de las promesas que deben cumplirse en la persona del estudiante: formarlo para la vida y formarlo para el trabajo, pues allí se fragua el futuro de la humanidad (Hans, 1995). Se forma para la vida con la sabiduría, y se forma para el trabajo con la ciencia, que es también una sabiduría si la puedo llamar de segundo grado. Por lo tanto, ir a la Universidad a estudiar, es también ir a recibir la sabiduría en la juventud de la vida, que será la compañera eterna por el resto de la existencia.

\section{La lectura ponderada a la historia}

Giandomenico sostiene que existe una conciencia árida, privada de sentido histórico que lee el mundo desde una inmanencia como si el pasado fuera el supremo valor; haciendo que se divulga que el rasgo más fuerte de nuestra cultura occidental, se debe entender desde "la Crisis, la decadencia y el declive" (Mucci, 2011:7); llaves de lectura para una comprensión de nuestra civilización. De esta mirada nace la nostalgia, el pesimismo, la angustia y el fatalismo.

Por lo anterior, aunque se afirma que con la modernidad se pasó del "homo sapiens" (racionalidad científica) al "homo sentimentalis" (racionalidad estética) (Lozano, 2004:11) y la triada metafísica persona, mundo, Dios (Criatura, Creado, Creador), se pensó de otra forma desarticulando sus intimas relaciones, reduciendo la naturaleza de cada una para desembocar en consecuencias complejas pues contradijo paradigmas: se difundió un pensamiento blando (los 'minirelatos') en contraposición a los llamados pensamientos fuertes (metarrelatos) liderados hasta el momento por los sistemas políticos, religiosos y los filósofos clásicos, la metafísica y la ontología y se difundió entre sus líneas matrices: proponer una antropología que no incluye hablar de la esencia humana, pues la naturaleza de la persona se fragmento en visiones; se defiende una moral subjetiva que predomina sobre la objetividad del bien moral contradiciendo la propuesta de una ética basada solidamente en los derechos humanos; se constata hablar de una racionalidad que paradójicamente desconfía en la propia razón como incapaz de encontrar la verdad; la norma de convivencia civil se funda en el derecho positivo del legislador que se inspira en los derechos de las minorías o mayorías, y se desconoce la ley natural, etc.

En la historia de la modernidad de pensamiento blando o débil (Lozano, 2004:11), se formó entonces una familia, una sociedad y un estado 'blando' que deben respetar toda propuesta civil en la democracia; deben respetar toda oferta 
espiritual, pues el sincretismo y eclecticismo como nunca toman fuerza de pensamiento y estilo vida debido a que la no exclusión y la tolerancia son unos de los principios de la ética ciudadana que se difunde globalmente.

Sin embargo, lejos de caer en un maniqueísmo o pesimismo frente a nuestra época, apareció positivamente la visión de la aldea global, la tendencia a la monocultura y el fenómeno de la convergencia desarticulando las exclusividades y los monopolios, para volcar las culturas en trabajos comunes, pues todo tiende a converger: la cultura, la economía, el arte, la religión, la política y la educación convergen; los estados tienden cada vez más silenciar su confesión religiosa para hablar de espiritualidad mas no de credos; las empresas pequeñas y las multinacionales se unen en alianzas; la comunidad europea se solidificó en una sola moneda; se propone una ética universal basada en los derechos humanos como común denominador (Vidal, 1999:111); la Declaración de Boloña expresa la unidad de la comunidad europea de una educación para formar ciudadanos en donde no hay fronteras de nacionalidad, pues los une el conocimiento; las comunidades científicas esparcidas por los estados del planeta investigan en conjunto trabajando en la solución pandemias; la arquitectura propone el proyecto de las casas autosuficientes; el mundo como habitat toma fuerza de valor por un ecologismo totalizante en donde cada vez se comprende que los actos particulares afectan el devenir del planeta; Twitter, Google, Facebook generan la convergencia de millones visitas de encuentros virtuales (Spadaro, 2009:17-28).

La lectura crítica pero ponderada de la historia es una estrategia pedagógica en el repensar la formación humana, pues es elevar los ojos a la contemplación de la historia pero bajo la oscilación del péndulo que se mueve entre la esperanza y la desesperanza; es educar para el discipulado de la crítica y el optimismo de la historia que llega.

\section{Universidad, verdad e ideologias}

\section{"La verdad es la adecuación del intelecto a la realidad objetiva"}

(Santo Tomás)

Sin desconocer la naturaleza humana y la cultura, la persona siempre será presa de intereses ideológicos, y el tema de las ideologías está relacionado con la verdad, valor constitutivo, epistemológico y trascendental de la esencia de la universitas.

El novecientos ha sido catalogado por algunos (Bracher,1984), como el siglo de las ideologías: socialismo, nacionalismo, liberalismo, racismo, fascismo, comunismo, capitalismo, etc. Por su parte, en los finales de los años setenta un documento señalaba los peligros de las ideologías que portan el psicologismo, el 
cientismo, el determinismo, el liberalismo capitalista, el colectivismo marxista y la doctrina de la seguridad nacional (Puebla, 1979:535-554).

En la modernidad, existen cantidad de ideologías que se venden y se consumen, pero sus efectos debilitan la verdad de la triada: persona (Criatura), del mundo (Creado) y de Dios (Creador).

Desde un sentido negativo, una ideología pretende definir la realidad desde una parte, sin tener en cuenta toda la realidad, porque busca reducir, manipular, instrumentalizar la esencia, a los intereses de alguien o de un grupo por medio de un discurso atrayente, fascinante, útil y autosuficiente.

Una ideología nunca se preocupara por presentar la verdad antropológica de la persona, pues no le interesa realmente a la persona (Otero, 1990:2-11), su verdad objetiva. Con las ideologías las personas y los grupos humanos quedan limitados y reducidos al poder absoluto de la sola interpretación parcial de la razón, de la mente, del placer, del consumo, de la ciencia, del estado, de la economía, del sexo, de la salud, del conocimiento etc.

Sobre este tapete, otro desafío para repensar la formación humana es la lectura a los padres ideológicos de la modernidad (Mucci, 2002:132-139), de modo que se conozcan, y en términos de la ilustración la persona del estudiante aprenda a tomar frente a ellos la ética de la mayoría de edad.

El subjetivismo radical-individual y el libertinismo: El subjetivismo rinde culto al yo, haciendo de él un ídolo que decide lo verdadero, lo justo, lo bueno. Este 'yo' encierra a la persona y la conduce a que rechace lo que suena a estructuras, obligaciones, absolutos morales y compromisos permanentes con otros. Este 'yo' genera un optimismo en la razón, en los juicios y en su pensamiento como confianza prometeica en si, en los poderes espirituales, donde el sujeto (el "homo potens" Lozano, 2004:13), es capaz de crear un nuevo habitat, vencer los obstáculos, la enfermedad, los sufrimientos (menos la muerte).

El culto al yo lo lanza a vivir a las personas en un individualismo circular y egoísta; por eso se cuida y defiende lo suyo y cuando encuentra obstáculos a la expansión de su 'yo', de su subjetividad, se hace lo que sea para eliminar al otro que le estorba planes, proyectos y deseos. Por eso es capaz de acabar con la vida ajena y no se inmuta (García, 1995:66).

La ideología del subjetivismo se une con la defensa del relativismo y el pluralismo en todas sus manifestaciones puesto que no hay una verdad única del mundo y de la vida. No hay verdades absolutas en la política, en la moral, en los modelos de familia, en la forma de vivir la sexualidad, en la religión. Por eso se resalta la tolerancia en pro de una convivencia pacífica sin dogmas, y el gusto por el pluralismo social se entiende; porque allí tiene cabida la subjetividad, en 
una sociedad compuesta por extraños morales (D’Agostino, 1998: 17). Este ambiente hace perder los horizontes de referimiento y de seguridad.

La ideología termina en afirma la libertad radical y el libertinaje. La libertad se entiende sólo como capacidad de elección autodeterminación e individualismo, olvidando la libertad como relación que tiene con la verdad, con la responsabilidad, y con la capacidad de vincularse a las personas. Su libertad es libertad de sí y para sí.

El securalismo, el laicismo y el indiferentismo: De la secularización se ha pasado al secularismo que es el pensamiento que proclama la autonomía radical de lo temporal sin referencia a lo religioso, ignorándolo o excluyéndolo expresado en un laicismo que afirma abierta o sutilmente, la persecución concreta frente a la Iglesia por parte del Estado (en casos una especie de cristianofobia), o en un ateísmo radical.

El laicismo hijo del proyecto iluminista coloca la razón, la ciencia y el progreso como faros de luz para crear una nueva civilización, pero se vive la paradoja por otros efectos: convirtió a las personas en consumidoras irracionales, en agnósticas, nihilistas, e indiferentes frente a lo religioso. En este ambiente la diosa razón duerme y la mente viaja con la imaginación. Para el laicismo la ciencia es la forma más elevada de conocimiento y modelo de vida. El laicismo llega a violar el derecho a la libertad religiosa que implica elegir una religión y confesarla públicamente.

Estos dos fenómenos: el secularismo y el laicismo terminan por propagar un indiferentismo hacia lo religioso, que conduce a que se puede vivir sin religión, sin sentido de lo sacro y lo profano. Se puede vivir sin Dios pues hoy todo se volvió equívocamente sacro, puesto que las personas hicieron de su vida, del estudio, del confort, de los títulos, del progreso, del placer, del estado, un 'dios'.

Con esta ideología, se pierde antropológicamente la dimensión vertical en la persona. La razón abierta a la trascendencia se cierra y lo único que existe es el estado positivo delineado por el utilitarismo, el pragmatismo y el cientismo. El secularismo, el laicismo y el indiferentismo llevan a callar la religión tradicional, a sofocar la voz de Dios mediante leyes y nuevas constituciones políticas, y a oír solo la criatura. El presente, el pasado y el futuro se miran sin fe, pues no hay historia de salvación, no hay diálogo con Dios en la historia. La esperanza no es trascendente sino intramundana.

La búsqueda de nuevas emociones religiosas: ideología que se entiende como el extremo de la anterior. Se comprende como el nomadismo espiritual, el cual consiste en ir y consumir otros ritos, momentos sacros, cultos de todo tipo donde hay numerosos adeptos y nuevos profetas. Estamos frente a la paradoja del retorno de lo sagrado de forma incomparable donde el fundamentalismo y el integrismo religioso renacen. 
Hoy todas las religiones y propuestas espirituales son válidas, hoy es mas atrayente seguir los profetas del oriente lejano con sus teorías de trasmigración de las almas; hoy es mas atrayente seguir los profetas del occidente que le dan culto a los poderes de la mente capaz de solucionar todo; hoy el cristianismo es una opción mas de las tantas que cualquier persona puede encontrar en la aldea global, pues el mundo esta reencantado por nuevas ofertas religiosas, entre ellas la magia o pseudo religiosas como el consumo de las drogas sintéticas.

Por eso terminamos encontrando gente que piensa y actúa así: "rechazo al rol de la Iglesia (Cristo Si, Iglesia No), rechazo al rol único de Cristo (Dios Si, Cristo No), rechazo al referimiento a un Dios personal (Religión Sí, Dios No), rechazo al rol de la Iglesia y de Cristo mas no de religión (Religión Si, Iglesia y Cristo No)" (Comissione per la Pastorale Universitaria, 1997: 14).

Por estar en una cultura pluralista se debe dar cabida a toda creencia, a toda forma de práctica religiosa, callar la religión tradicional para que se pueda dar culto al mal, en esta cultura multirreligiosa (Garcia, 2002). La identidad cultural que se forma con lo religioso, y que es patrimonio de siglos, de generaciones y de familias, pasa a ser identidad de una cultura abierta a todo un politeísmo religioso.

El naturalismo materialista y el cientismo: Ideología que suprime toda diferencia cualitativa entre el resto de la naturaleza y los animales; se niega lo lo específicamente humano. Por esta vida se enclaustra más a las personas en la inmanencia y se le cierra la trascendencia.

De aquí surge un concepto de persona, donde lo espiritual, el alma se equipara con la mente que tiene un final con la muerte de la persona. El hombre es un animal superior, y no por su estructura natural; siendo igual con las otras especies, los animales inferiores tienen derechos (La Civilta Cattolica, 2002: 602-604).

El naturalismo materialista, en el campo sexual apoyado por la jurisprudencia va haciendo legal cualquier comportamiento sexual, pues se considera natural. Por su parte el cientismo ha generado un lema cultural: todo lo técnicamente posible es éticamente posible, de ahí que se puede investigar, clonar, manipular las células germinales del embrión, congelar embriones supernumerarios, etc. El cientismo crea una criatura amparada en el mito prometeico de la técnica.

La dependencia de los medios de comunicación: El influjo de ellos es difícil de suprimir (Restrepo, 2008: 93-106), pero no se puede negar el totalitarismo que ejercen, llegándose a querer imitar los paradigmas de persona, sociedad y vida que allí se proponen.

Los medios de comunicación condicionan y plasman desde la infancia a toda persona; le cultivan y le despiertan la capa epidérmica que en muchos casos 
genera la educación para vivir en la dependencia de las emociones, los deseos, las pasiones, los sentidos, los impulsos, etc. Por eso tenemos como resultado un ser 'mediático', epidérmico y su vida gira alrededor de los medios de comunicación e información.

Encantado de escuchar y estar junto a este 'padre ideológico', que lo instruye y lo forma para que sea un ciudadano cosmopolita, experimenta una contradicción: vive en la aldea global, en una monocultura comunicado con todos en la aceleración, en las comida rápidas, en la velocidad de las autopistas, en la velocidad tecnológica por medio del correo electrónico, fax, internet, celulares, etc; y por otro lado existencialmente se siente solo y abandonado, pues las relaciones que entabla son de producción, de resultados. Existencialmente esta comunicado pero sigue incomunicado en problemas vitales, por eso es fácil manipularlo en red y se programan suicidios colectivos. El 'padre ideológico' de los medios, formó un hijo calculador, practico, frío e individual que vive bajo la psiquis colectiva de la dependencia de los medios de comunicación, difícil de controlar.

\section{Nodos tematicos para la unidad humanista en la educacion superior}

Y frente a este breve panorama, ¿Que se puede hacer desde la educación superior?, bien afirma un experto: "La universidad, en tanto producción cultural de la sociedad, se encuentra situada en un contexto histórico y en una sociedad particular, de la cual no puede permanecer aislada. La universidad debe tener la capacidad de responder a las necesidades de su entorno, debe ser capaz de ver al futuro, de identificar los nichos y los cauces apropiados para una transformación de la sociedad hacia un estadio donde el hombre pueda lograr un desarrollo más justo y pleno. Debe, asimismo, formar a los profesionales que la sociedad demanda sin olvidar que son hombres quienes, para situarse en esa sociedad y contribuir a resolver sus necesidades, requieren de una formación humanística" (Ibarra, 2003).

Pienso que los siguientes referentes pueden dar unas bases para hablar en la modernidad de un renacimiento humanístico en las aulas de la educación superior o de un reorientar unos aspectos para la educación de máximos, la educación para la vida y el trabajo, el contemplar la historia y hacer contrapeso al influjo de las ideologías:

El rol del intelectual humanista: un problema por resolver en la claustros de educación universitaria es el de convencerse que el problema no es la universidad, sino las personas que laboran en ella. Me refiero concretamente a la vivencia, por ejemplo, cristiana de sus miembros, directivos y concretamente de sus profesores, pues como dirá Humberto Pelaez S.J: "Estamos convencidos 
de que la enseñanza fundamental se imparte a través del comportamiento de los docentes. Es inevitable que en el proceso de enseñanza-aprendizaje los estudiantes se vayan identificando con alguno o algunos de sus docentes. Se sienten particularmente atraídos por su personalidad o por sus dotes intelectuales o por su éxito profesional. A través de esa identificación se van infiltrando los valores del profesor. Por eso ningún proceso educativo es neutral en cuanto a la trasmisión de valores. El comportamiento de los profesores es la cátedra por excelencia donde se enseña la Ética" (Peláez, 1994:8-9).

Aquí entra en juego la figura del intelectual humanista y del humanista católico (ausente quizás hoy en nuestra cultura), que comparte con todo intelectual la pasión por la verdad. Este intelectual es capaz de respetar los límites del saber que profesa, es además capaz de hacer abrir el horizonte a los estudiantes de “aquellas inquietudes últimas y fundamentales” (Peláez, 1994:23).

La figura novedosa del intelectual humanista está relacionada hoy con el reto de enriquecer más la oferta del estudio de las humanitates en los curriculum confrontando las estrategias pedagógicas, conjugando el humanismo clásico y los nuevos aportes de humanistas (Low, 2004) y escuelas emergentes; haciendo extensiva la figura del intelectual humanista en los cursos de posgrados, y la importancia de la asociación y el trabajo colaborativo en redes de investigación.

Suscitar la búsqueda por la Sapienza: entendida como aquella ciencia especulativa, que da los secretos más profundos para encontrarle a la ciencia, a la técnica, a la vida, al trabajo, y a un título el sentido. La universidad debe por lo tanto formar en lo permanente y en lo cambiante de la educación (Altajeros, 1990). Lo permanente en la educación es la persona, los valores inmutables; pues lo que cambia es el ambiente, la tecnología y la evolución vertiginosa del conocimiento para aplicar a la realidad.

Lo que permanece entonces es la persona, un ser libre con dignidad, y con eternos dilemas por solucionar: “¿Qué es el hombre?, ¿Cuál es el sentido del dolor, del mal, de la muerte, que a pesar de tantos progresos hechos, subsisten todavía?, ¿Qué valor tiene las victorias logradas a tan caro precio?, ¿Qué puede dar el hombre a la sociedad?, ¿Qué puede esperar de ella?, ¿Qué hay después de esta vida temporal?" (Concilio Vaticano II, 1968).

Si la universidad no educa en lo permanente, encontraremos paradojas como: ver muchos técnicos, estudiantes en pregrado, egresados, profesionales con postgrados, pero el titulo (o los títulos) solo les ha servido para crecer en un trabajo económicamente, adquirir status, contribuir con la trasformación de un mundo mas desarrollado; más sin embargo, su vida afectiva está destrozada, con intentos de suicidio, o centrados solo en hacer dinero como sea. También encontraremos, tantos desempleados con títulos que sufriendo una profunda negación de un derecho fundamental que es el trabajar, sufren además porque 
no saben vivir 'su estar desempleado' con la sabiduría de la vida que no siempre da un diploma.

La formación en la educación superior para lo superior, debe entonces ser capaz de formar en los alumnos una sabiduría global: ser competente en la justicia social, y poseer la capacidad y tenacidad de vencer y afrontar los "nuevos flagelos" (García, 2005:32), del comienzo del siglo XXI, pues los datos de la vida cotidiana nos confirman que un diploma o un título no hace inmune al profesional frente al suicidio, contraer una ETS, o asumir estilos de vida no saludables; además se constata que los habitantes de la civilización de hoy sufren de la melancolía que les cambia su rostro y su alma; de la indiferencia que los lleva a no importarles nada y caer en un nihilismo de la vida; de la depresión frecuente que los encierra en un túnel sin salida deseando el suicidio; del aburrimiento de la vida y de la rutina diaria; y de sus miedos y temores frente al presente y al futuro, pues se dan cuenta por un lado, que la racionalidad técnica es una bomba de tiempo y que, por otro lado todo pasa y no hay nada sólido en que apoyarse.

La pasión por la Verdad: porque estudiar es venir al encuentro con la verdad. Antropológicamente hay un deseo por la verdad y una orientación inagotable de la razón, debido a que la especie humana se resiste a vivir en la duda, en la incertidumbre o la mentira.

Agustín de Hipona decía: "El deseo de alcanzar la verdad me roía el corazón" "¡Verdad!, ¡Verdad! Con qué intensidad suspiraba yo por ella desde el fondo de mi alma", "yo hambriento de verdad, me ofrecían otras cosas el sol y la luna, pero no ella" (San Agustín, 1995:41.91).

No obstante hoy parecería que hablar de la verdad en la universidad es incómodo, porque estamos frente a unas de las épocas, en donde la nominación del vocablo 'verdad' suscita como nunca discusiones, rechazos, debido a la dictadura del relativismo que se expande con muchos seguidores. Esta mentalidad transmitida, permea la cultura, la educación; terminándose por generar una ofuscación en la razón y la conciencia en torno a la verdad, las cuales salen como humilladas y confusas sin saber si existe el esplendor de la existencia de la verdad.

En este marco situacional, la cultura y la universidad siguen teniendo hoy un cometido importante en la educación de la verdad, pues de la forma como se hable de la verdad se verá también un resultado en la educación ética, en las costumbres y en la epistemología de cada ciencia.

La historia del caminar en la universidad refleja entonces, la búsqueda de la verdad, la pregunta por la verdad como la hizo Pilatos: “Qué es la verdad?”; y la dialéctica que conlleva a encontrarla, adherirse o rechazarla. 
El sentido de la Felicidad: La experiencia de la felicidad es un dato de la existencia humana; detrás de muchas acciones, las personas buscan la felicidad, y en el caso de la universidad, se estudia para ser feliz; bien afirma el filósofo estoico romano Lucio Anneo Séneca: "Todos quieren vivir felices, mi querido Galión” (Seneca, 1997:63).

La cultura moderna busca alienar y engañar a las personas en el tema de la felicidad, colocándoles proyectos y modelos para que alcancen 'breves felicidades' y lanzándolos a buscar la felicidad donde no está, provocando así en tantas personas la desesperación por la "felicidad inmediata ", la dificultad en elegir (Zenit, 2005) y el pronto aburrimiento.

Es necesario admitir que la sociedad moderna y materialista aun haya creado un mundo más rico de condiciones de vida impensables al de hace 50 años, no ha logrado satisfacer las aspiraciones de la gente en torno a la felicidad, que es un natural apetito o a una presencia operativa de deseo (Chalmeta, 1996:19).

La universidad debe preocuparse por este tema existencial y hay que advertir que la cultura, la educación, pueden caer en el peligro de educar para la infelicidad y convertir personas con una existencia desdichada; siendo la causa de esta situación el no haber encontrado en vida guías, maestros, espacios y reflexiones serias para determinar un orden ideal de vida buena.

Educar para el encuentro con la Belleza: "La belleza salvará el mundo" dijo un literato ruso (Dostoievski). El estudio de las "humanitates" elevan el corazón y la razón hacia lo espiritual, y con ello hacia el encuentro de la belleza que se descubre.

Benedicto XVI afirma: "Todos reconocemos que la belleza, como un espejo de lo divino, inspira y vivifica los corazones y mentes jóvenes, mientras que la fealdad y la tosquedad tienen un impacto deprimente en las actitudes y comportamientos".

De lo anterior surge la importancia de una formación humanista unida con el arte y la estética, las cuales sean capaces de elevar, al joven, al profesional que retorna a los posgrados para que se encuentre con la belleza, pues ella abre al hombre a una profundidad, al misterio que en ultimas es Dios, y para los creyentes, es Cristo, belleza del Padre a la humanidad.

El encuentro con la belleza eleva a la persona "por encima de las miserias y de las vulgaridades del mundo hacia las cosas más altas, grandes, a la medida de una imagen superior, la imagen de Dios" (Tottus Tuus, n.9, 2007).

La belleza, en últimas, es "espejo de lo divino, orienta y estimula el ejercicio responsable de la libertad" (Consejo Pontificio de las Comunicaciones, 2007) 
y los hombres y las mujeres renacen a lo superior, entonces es cuando se encuentran de nuevo o por primera vez con la belleza.

Educar para el paso de las antropologías del Yo a las Antropologías del Tú: La universidad por el proceso cultural ha caído en la trampa de olvidar la función social que tiene el conocimiento; y sus egresados están viviendo en el engaño de adquirir conocimiento para competir, para el provecho individual, para el lucro, y adquirir rápidamente posición social. Se reconoce no obstante todos las acciones que se realizan hoy con referencia a la proyección social y el voluntariado.

Sin embargo la antropología filosófica sigue siendo una piedra angular en el renacimiento de las humanitates en la modernidad, pues con ella inspirada en una visión "adecuada" de la persona, favorecerá el movimiento centrifugo para que la existencia no quede viviéndose de forma centrípeta.

De ahí la importancia de seguir trabajando el paso de las antropologías del Yo al Tú, aprendiendo a < contemplar al otro como tierra sagrada $>$. Contemplar la vida, toda vida en el nuevo jardín del edén del siglo XXI.

Las antropologías del tu conducen a la ética del don, del amor y por ello es importante encontrar los maestros del don: "ellos nos enseñan a dar prioridad a la importancia de ponerse en camino hacia el otro. Los maestros del don generan la cultura del don que cura a otros, sana las carencias que todos llevamos en la afectividad herida en el hogar o por el entorno; la cultura del don hace sentir amado al otro, acogido, socorrido, escuchado, y esto ya ejerce un poder curativo en el corazón de alguien" (García, 2005:132).

En los términos de Jacques Maritain, la educación de las antropologías del yo al tu, llevan a que las personas en la modernidad vivan un humanismo heroico y este, según el francés, hace posible que una persona comience realmente a hacerse santa.

La propuesta de una ética universal: aunque este tema ha encontrado una salida en la Declaración universal de los derechos del hombre (1948), desafortunadamente ha tenido sus sorpresas pues la verdad objetiva del obrar frente a los derechos, se debilita por la jurisprudencia o el relativismo. De ahí que se propone converger también en una ética universal que se fundamente también en la ley natural (La Civiltá Cattolica, 2009: 533-539), pues la razón humana es capaz de leer en cualquier ciudadano, el llamado a cumplir el bien y evitar el mal.

Sin embargo esta propuesta debe llevar implícitamente el primado del mayor principio ético "el respeto y la promoción por la dignidad humana" (García, 2008:78) y de un principio no negociable: "protección de la vida en todas sus etapas, desde el momento de la concepción hasta la muerte natural" (Benedicto XVI, 2006). 
La búsqueda de la ética universal toca inevitablemente la formación en valores morales. Subrayo la solidaridad: Las Naciones Unidas establecieron para el 30 de Agosto, el día internacional de la Solidaridad, con el fin de que en esta fecha se promuevan y fortalezcan los ideales de solidaridad, como valores fundamentales para las relaciones en y entre las naciones, los pueblos y las personas. Juan Pablo II afirmó: “es preciso asegurar una globalización en la solidaridad, una globalización sin dejar a nadie al margen” (Mensaje para la Jornada mundial de la paz de 1998); y la virtud de la responsabilidad social en el contexto del manejo de lo privado y lo público.

Defender el habitad de vida: El planeta y los pobres del planeta. El mundo se ha convencido que la paz verde y social tan esperada por la modernidad no tiene efectos tan rápidos pues no desaparece sino que crece la tensión planetaria sobre el agua, la contaminación, el calentamiento global, el hambre (Occhetta, 2009:365-377).

Se requiere precisar ante todo, en este cometido, las nuevas formas modernas de idolatría de la naturaleza que pierden de vista al hombre, pues en los debates de los últimos años sobre preocupaciones demográficas, aparecen las políticas que buscan limitar la población, con la vista en la conservación del medioambiente, por medio del aborto y la esterilización. Estos son ecologismos que frenan una autentica ecología humana (García, 2009:45-54), pues no relacionan adecuadamente la naturaleza de los términos población, medio ambiente y desarrollo.

En este contexto se mantiene la discusión entre grupos ecologistas con tendencia a estar más preocupados por el ecosistema, pero que no se inmutan o se pronuncian frente a tantas tragedias humanas. Para estos grupos la presencia humana disturba el equilibrio ecológico natural.

Pienso que en la modernidad se ha roto el principio de la triada metafísica (criatura, creado, creador). Debe volver a escucharse bajo un sano pluralismo el principio: "La naturaleza es para el hombre, y el hombre es para Dios" (Card Martino). Con esta afirmación se defiende dos cosas: no endiosar lo creado y el hombre no puede caer en la instrumentalización de lo creado.

Y frente a los pobres del planeta el mejor antídoto es la lucha contra la corrupción, y un estilo de vida que logro colocar la sobriedad frente al consumo, lo necesario frente a lo superfluo. 


\section{Conclusiones}

1. La universidad, como espacio de humanismo, tiene el cometido de formar personas para la vida y el trabajo. Si no mantiene este equilibrio, el alma mater nutrirá mal a sus hijos y formará paradójicamente monstruos educados que siguen suscitando miedo.

En la modernidad la Universidad en su camino convergente, para ofrecer el mejor nutriente, debe difundir el principio que la formación humana no solo es una tarea específica de un Departamento, Instituto, o personas cualificadas; sino la tarea connatural de toda la comunidad preocupada permanentemente por dignificar la estadía del estudiante.

En el seno de la universitas moderna, se debe realizar una Pastoral de la Inteligencia capaz de presentar a todos sus miembros la vivencia de unos valores- máximos, movidos no solo por el derecho de justicia, sino movidos por la Caridad, esto es hacer el bien no por altruismo, sino por contemplación del rostro del otro que es también presencia de Dios

2. Se requiere metafóricamente de una nueva Paidea humanista de carácter global, que forme personas criticas para desarticular las ideologías dominantes, discernimiento para ponderar en los procesos globales los valores históricos, fortaleza para mantener la identidad personal y cultural en el mundo cambiante; apertura a lo global y lo universal para hacer de la "sociedad una comunidad de hombres y de pueblos" (Martinez, 2007) y alimentar razones serias frente a la mirada que tengamos de la persona, del valor de la vida, de la magna cuestión: ¿De donde vengo, a donde voy?, ¿Cuál es el sentido de la vida?; pues debilitada la antropología (la criatura) con sus profundos interrogantes, se debilita el mundo (lo creado) y se debilita las relaciones con la divinidad (el Creador).

3. Aunque en la modernidad es fuerte el modelo del "homo potens" amparado en el poder de la técnica y ciencia, la genética y la razón, así como el modelo del "homo sentimentalis" amparado en la tiranía de los deseos, los placeres y satisfacer necesidades; la educación superior debe escuchar la razón universal que admite en ellos una razón blanda (pensamiento débil) y no son el referente de inspiración para la juventud, pues se constata en medio de los avances del progreso un pavor: "Millones de personas humanas son matadas en muchas formas: homicidio, suicidio, infanticidio, uxorcidio, parricidio, droga, alcohol, armas, deportes peligros, juegos trágicos, velocidad y desgracias en el asfalto. Otros millones mueren, son matados, por desesperación; por hambre, por sed, por falta de ayuda o por tardíos o inadecuados tratamientos médicos; por impericia o negligencia; por insuficiencia de personal sanitario, de camas, de equipos necesarios; por explante de órganos humanos vitales antes de que el paciente haya muerto" (Di Muro, 2006:44). 


\section{Referencias bibliográficas}

Asamblea del Episcopado Latinoamericano. 1979. Documento de Puebla. nn, 535-554.

Altajeros., F. et al. 1990. Lo permanente y lo cambiante en la educación. Navarra, Eunsa.

Benedicto XVI. Discurso a los participantes de las Jornadas de estudio sobre Europa organizadas por el Partido Popular Europeo, 30-03-06; Ver también Sacramentum Caritatis, $n^{\circ} 83,22-02-07$.

Borrero, A. 1994. Simposio permanente sobre la Universidad, Octavo Seminario, Conferencias, I. II. Bucaramanga, 1994-1995, p.30.

Bracher, K. 1984. Il novecento, secolo delle ideologie. La terza, Roma-Bari, 1984.

Buttiglione, R. 1984. El Hombre y el Trabajo. P.8. Encuentro, Madrid.

Concilio Vaticano II, Constitución Gaudium et spes, n.10.67.

Chalmeta, G. 1996. Etica Especial. El orden ideal de la vida buena, Navarra, EUNSA 1996, p.19.

D’Agostino, F. 1998. Bioetica, Torino, Giappichelli, p.7.

Declaración universal de derechos humanos, 1948, Art, n.23.

Di Muro, V. 2006. "La sociedad moderna en conflicto entre cultura de la vida y cultura de la muerte", Dolentium Hominum, 62, 2006, n.2, p.44.

Diòcesi Di Roma, Comissione per la Pastorale Universitaria, 1997, p.14.

Dostoievski, F. El Idiota, p. III, cap. V.

Editoriale “Alla recerca di un'etica universale”, La Civiltà Cattolica, 3816, 20 giugno 2009, pp.533-539.

Editoriale, sobre el martirio de Annalena Tonelli, La Civiltà Cattolica, 3681, 1.Nov. 2003, p.215.

Editoriale, La Civiltà Cattolica, 3637, Ene.5.2002, p.8.

Eliade, M. Lo Sagrado y lo Profano, pp. 169-179.

García, S. 2002. Dios no ha muerto todavía. Retos y peligros del retorno a dios en un mundo multirreligioso, en El Informativo. Revista de la Arquidiócesis de Bucaramanga, Mayo, 2002, p10. 


\section{Saúl Ernesto García Serrano}

Repensar la formacion humana en la modernidad. Artículo de opinión.

García, S. 2006. Educar es transmitir sabiduría, Perfiles, 2 Universidad de Santander, 2006, p.48-58.

Garcia, et al. 2009. Educación y Poesia, Universidad de Santander, 2009, pp.45-54.

García, S. 1995. Ética para el tercer milenio, Temas, Universidad Santo Tomás de Aquino, 3, 1995. p.66.

García, S. 2008. Formación Profesional en Bioética, Bogotá, San Pablo, 2008, pp.78-82.

García, S. 2005. Vivir en la donación del ser. Bogotá, Paulinas.

Hans, J. 1995.El principio de Responsabilidad. Herder, Barcelona.

Ibarra, J. 2003. "La universidad necesaria" Revista Electrónica de Investigación Educativa, 5 (1), http://redie.uabc.mx/vol5no1/contenido-ibarra.html (consultado el 21-09-09).

Juan Pablo II. 1991. Carta. Encíclica. Centesimus Annus, n.43.

Juan Pablo II. 1995. Carta Encíclica, Evangelio Vitae, nn, 21-22.24.

Juan Pablo II. 1998. Carta Encíclica Fides et Ratio, n.90.

Juan Pablo II. 1981. Carta Encíclica, Laborem Exercens, nn.5.7.

Juan Pablo II. 1993. Carta Encíclica, Veritatis splendor.

Juan Pablo II. 1995. Uomo e donna lo creó, Roma, Editrice Vaticana, p.72.

Lozano, J. 2004. "Rasgos del pensamiento postmoderno y la depresión”, Dolentium Hominum, 55. 2004, p.11.

Low, M. 2004. Mas Platón y menos prozac. Ediciones B, 2004

Martínez, A. 1007. "Hacer de nuestra sociedad una comunidad de hombres y de pueblos", Communio, 5, Verano 2007, Madrid, Ciudad Nueva, pp.63-70.

Ministerio de Educación Nacional y ICFES. 2001. Bases para una politica de estado en materia de educación superior, Bogotá, Marzo 17,2001. pp.89-92. Este documento recoge en parte la tesis de Edgar Morin sobre Los siete saberes necesarios para la educación del futuro.

Ministerio de educación nacional. 1992. Ley 30, 1992, art.6

Mucci, G. 2002. "Dio non è ancora morto", La Civilttà Cattolica, 3642, Mar 16.2002, pp576-585. 
Mucci, G. 2009. "Il totalitarismo ideologico della scienza", La Civilttà Cattolica, 3814, Roma, 16 maggio 2009, pp.319-324.

Mucci, G. 2002. "La malinconia nel tempo della postmodernità", La Civilttà Cattolica, 3650, Jul 20.2002, pp.132-139.

Mucci, G. 2002. Una Recente Discussione sull'iluminismo, La Civilttà Catolica, n.3637, Ene 5.2002, p.19.

Mucci, G. 2011. Discernimiento dei Segni dei tempi e i motivi di speranza, en La Civilta Cattolica, 3861, 7, Mayo, 2011.

Occhetta, F. 2009. "La piaga della fame nel mondo", La Civilttà Cattólica, 3821, 5 settembre 2009, pp. 365-377.

Otero, O. 1990. Influencia de las Ideologías en la Familia. Instituto de Ciencias de la Educación. Universidad de Navarra, 1990, pp. 2-11.

Pelaez. H. 1994. ¿Un lugar para la Ética en la Unversidad?, en Simposio Permanente sobre la Universidad, Octavo Seminario General, 1994-1995, pp, 8-9.

Prada, B. 2002. En Diario Vanguardia liberal, Dominical, Feb.3.2002, p.5.

Raabe, P. \& Schnidt W. 1979. La Ilustración en Alemania, Hohwacht verlas, 1979, Boon, pp.9-15.

Reale, G. 1996. La Sabiduría antigua, Herder, Barcelona, 1996, pp.19-35.

Reale. 1996. La Sabiduría antigua, Herder, Barcelona, 1996, pp.19-35.

Reina, J. 2000. Punto De Encuentro, Informativo Sena Santander, Mar 2000, p.3-4.

Restrepo, J. 2008. ¿Qué ser humano producen los medios?, en Humanismo y Bioética en la Universidad. Cultura y Derecho a la Vida, Bucaramanga, Universidad de Santander, Vol II, 2008, pp.93-106.

Revista Temas, Universidad Santo Tomás de Aquino, 3, 1995. p.66

Salazar, F. 2000. ¿Que hacer?.En Periódico Cátedra Libre UIS, Vanguardia Liberal, Sep 3. 2000.

San Agustín. 1995. Las Confesiones, Madrid, Cuadernos Palabra, 1995, pp.91.41

Seneca. 1997. Sobre la felicidad. Sobre la brevedad de la vida, Edad, Madrid, 1997, p.63.

Spadaro, A. 2009. "Twitter cambiararà la nostra vita? ”, en Revista La Civilttà Cattolica, 3817, 4 luglio 2009, pp. 17-28. 


\section{Saúl Ernesto García Serrano}

Repensar la formacion humana en la modernidad. Artículo de opinión.

Totus Tuus, n.9, 2007

Vidal, M. 1999. 10 palabras clave en Moral del futuro, Verbo Divino, Pamplona, 1999, p.111.

ZENIT.org. 2005. Etica y Felicidad en la cultura, 25.Jun.2005 